\title{
Contribution of bone marrow-derived cells to in situ engineered tissue capsules in a rat model of chronic kidney disease
}

Citation for published version (APA):

Bezhaeva, T., Geelhoed, W. J., Wang, D., Yuan, H., van der Veer, E. P., van Alem, C. M. A., Damanik, F. F. R., Qiu, X., van Zonneveld, A-J., Moroni, L., Li, S., \& Rotmans, J. I. (2019). Contribution of bone marrow-derived cells to in situ engineered tissue capsules in a rat model of chronic kidney disease. Biomaterials, 194, 47-56. https://doi.org/10.1016/j.biomaterials.2018.12.014

Document status and date:

Published: 01/02/2019

DOI:

10.1016/j.biomaterials.2018.12.014

Document Version:

Publisher's PDF, also known as Version of record

Document license:

Taverne

Please check the document version of this publication:

- A submitted manuscript is the version of the article upon submission and before peer-review. There can be important differences between the submitted version and the official published version of record.

People interested in the research are advised to contact the author for the final version of the publication, or visit the DOI to the publisher's website.

- The final author version and the galley proof are versions of the publication after peer review.

- The final published version features the final layout of the paper including the volume, issue and page numbers.

Link to publication

\footnotetext{
General rights rights.

- You may freely distribute the URL identifying the publication in the public portal. please follow below link for the End User Agreement:

www.umlib.nl/taverne-license

Take down policy

If you believe that this document breaches copyright please contact us at:

repository@maastrichtuniversity.nl

providing details and we will investigate your claim.
}

Copyright and moral rights for the publications made accessible in the public portal are retained by the authors and/or other copyright owners and it is a condition of accessing publications that users recognise and abide by the legal requirements associated with these

- Users may download and print one copy of any publication from the public portal for the purpose of private study or research.

- You may not further distribute the material or use it for any profit-making activity or commercial gain

If the publication is distributed under the terms of Article $25 \mathrm{fa}$ of the Dutch Copyright Act, indicated by the "Taverne" license above, 


\title{
Contribution of bone marrow-derived cells to in situ engineered tissue capsules in a rat model of chronic kidney disease
}

\author{
Taisiya Bezhaeva ${ }^{\mathrm{a}, \mathrm{b}}$, Wouter J. Geelhoed ${ }^{\mathrm{a}, \mathrm{b}}$, Dong Wang ${ }^{\mathrm{c}, \mathrm{d}}$, Haoyong Yuan ${ }^{\mathrm{c}}$, \\ Eric P. van der Veer ${ }^{\mathrm{a}, \mathrm{b}}$, Carla M.A. van Alem ${ }^{\mathrm{a}, \mathrm{b}}$, Febriyani F.R. Damanik ${ }^{\mathrm{e}}$, Xuefeng Qiu ${ }^{\mathrm{c}, \mathrm{g}}$, \\ Anton-Jan van Zonneveld ${ }^{\mathrm{a}, \mathrm{b}}$, Lorenzo Moroni ${ }^{\mathrm{e}}$, Song Li ${ }^{\mathrm{c}, \mathrm{d}, \mathrm{f}}$, Joris I. Rotmans ${ }^{\mathrm{a}, \mathrm{b}, *}$ \\ ${ }^{a}$ Department of Internal Medicine, Leiden University Medical Center, the Netherlands \\ ${ }^{\mathrm{b}}$ Einthoven Laboratory for Vascular and Regenerative Medicine, Leiden University Medical Center, the Netherlands \\ ${ }^{\mathrm{c}}$ Department of Bioengineering and Department of Medicine, University of California, Los Angeles, USA \\ ${ }^{\mathrm{d}}$ Department of Bioengineering, University of California, Berkeley, USA \\ ${ }^{\mathrm{e}}$ MERLN Institute for Technology Inspired Regenerative Medicine, Complex Tissue Regeneration, Maastricht University, the Netherlands \\ ${ }^{\mathrm{f}}$ Department of Medicine, University of California, Los Angeles, USA \\ ${ }^{\mathrm{g}}$ Department of Cardiovascular Surgery, Union Hospital, Tongji Medical College, Huazhong University of Science and Technology, Wuhan, China
}

\section{A R T I C L E I N F O}

\section{Keywords:}

In situ vascular tissue engineering

Chronic kidney disease

Hemodialysis vascular access

Bone-marrow lineage tracing

Foreign body response

\begin{abstract}
A B S T R A C T
Tissue engineered blood vessels (TEBVs) hold great promise for clinical use in patients with end stage renal disease (ESRD) requiring vascular access for hemodialysis. A promising way to make TEBVs is to exploit foreign body response (FBR) of polymeric rods used as templates. However, since the FBR predominantly involves bonemarrow (BM) derived cells and ESRD coincides with impaired function of BM, it is important to assess the generation of TEBVs in conditions of renal failure. To this end, we implanted polymer rods in the subcutis of rats after BM-transplantation with GFP-labeled BM cells in a model of chronic kidney disease (CKD). At 3 weeks after implantation, rods were encapsulated by tissue capsule (TC) composed of collagen, myofibroblasts and macrophages. On average, $13 \%$ of $\mathrm{CD}^{+} 8^{+}$macrophages were $\mathrm{GFP}^{+}$, indicating $\mathrm{BM}$ origin. Macrophage-to-myofibroblasts differentiation appeared to play an important role in TC formation as $26 \%$ of SMA ${ }^{+} / \mathrm{GFP}^{+} \mathrm{myofi}^{-}$ broblasts co-expressed the macrophage marker CD68. Three weeks after rod implantation, the cellular response changed towards tissue repair, characterized by $40 \%$ increase in $\mathrm{CD}^{+} 8^{+} / \mathrm{CD} 163^{+}$repair associated macrophages and 95\% increase in TGF $\beta$ and IL10 gene expression as compared to TCs harvested at 1 week. These results show that both BM derived and tissue resident cells, contribute to TC formation, whereas macrophages serve as precursors of myofibroblasts in mature TCs. Finally, the presence of CKD did not significantly alter the process of TC formation, which holds the potential to support our approach for future clinical use in ESRD patients.
\end{abstract}

\section{Introduction}

Patients with cardiovascular disease (CVD) or end-stage renal disease (ESRD) frequently require surgery to either replace diseased blood vessels or create a vascular access site for hemodialysis [1-3]. For this purpose, native veins are generally preferred due to superior patency rates when compared to prosthetic grafts, but often unavailable due to preexisting vascular pathology $[4,5]$. The failure of synthetic vascular grafts predominantly results from the development of intimal hyperplasia ultimately leading to graft occlusion, and a relatively high risk of infectious complications [6-8]. In recent years, various strategies to create tissue engineered vascular grafts have been developed in an effort to overcome current limitations of synthetic grafts and diseased native blood vessels [9-11]. Indeed, tissue engineered blood vessels (TEBVs) can be tailor-made, do not have inconvenient valves and sidebranches, are free from pre-existing vascular diseases and have the potential to adapt to changing hemodynamic conditions.

Our approach to generate autologous TEBVs in vivo is based on the foreign body response (FBR) directed to a subcutaneously implanted polymer rod that culminates in the formation of a fibrocellular tissue capsule (TC), that encapsulating the rod [12]. Upon extraction of the polymer rod several weeks after implantation, the remaining TC is grafted into the vasculature, whereupon it differentiates into a blood vessel. In this approach, the subcutaneous space is utilized as an in situ

\footnotetext{
${ }^{*}$ Corresponding author. Department of Internal Medicine, C7Q-36, Leiden University Medical Center, Albinusdreef 2, 2333ZA, Leiden, the Netherlands.

E-mail address: j.i.rotmans@lumc.nl (J.I. Rotmans).
} 
bioreactor to grow a completely autologous blood vessel. In a previous study in pigs, we demonstrated that upon vascular grafting, the TCs phenotypically differentiate towards a blood vessel, as demonstrated by enhanced matrix synthesis, differentiation of fibroblasts toward contractile vascular smooth muscle cells (VSMCs) and endothelialization of the luminal surface [13].

The dynamics of the FBR to implanted materials have been elucidated in detail [14]. The early phase of the FBR is characterized by the recruitment of inflammatory cells, which is followed by the formation of granulation tissue, ultimately resulting in a fibrocellular TC, which completely encapsulates the implanted foreign body [15]. However, the origin of the cells present within the TCs is still unknown. Understanding the origin of cells present in the TC is of vital importance for its application as vascular grafts, as various disease conditions such as diabetes mellitus, chronic kidney disease (CKD) and ischemic peripheral arterial disease coincide with impaired function of bone marrow (BM)-derived cells [16-18], which could hamper TC formation.

In the present study, we aimed to elucidate the contribution of BMderived cells in TC formation in a rat model of green fluorescent protein (GFP) BM transplantation [19]. Furthermore, we combined this model with a model of CKD to investigate its effect on TC composition.

\section{Material and method}

\subsection{Study design}

All the animal work was performed at the University of California, Los Angeles and approved by the institutional animal care and use committee. Five-weeks old male Sprague Dawley (SD) rats (200-250 g) were purchased from Jackson Laboratory (USA) $(n=27)$, transgenic enhanced GFP SD rats (SD-Tg (UBC-EGFP)2BalRrrc) were purchased from rat resource and resource center (University of Missouri, Columbia, USA) $(n=9)$. All animals were housed in the local facilities accredited by the American Association for Accreditation of Laboratory Animal Care and were maintained under controlled conditions of light, temperature, and humidity.

\subsection{Bone marrow transplantation}

After 1-week acclimatization to the new environment, SD-Tg (UBCEGFP)2BalRrrc rats were used as donor rats for the extraction of bone marrow cells (BMCs). BMCs were harvested from the femurs and tibias of 6 to 8-weeks-old SD-Tg (UBC-EGFP)2BalRrrc rats and the nucleated cells were enriched by lysing red blood cells with Red blood cell lysis buffer (1.2 mL, Sigma, St Louis, MO, USA). The recipient SD rats were lethally irradiated with two apart doses of 5,5Gy each (11Gy in total) with a $4 \mathrm{~h}$ brake using a cobalt- 60 gamma source. BMCs $\left(2^{*} 10^{7}\right)$ were injected via tail vein into recipient rats $24 \mathrm{~h}$ after irradiation. To prevent infections after BM transplantation antibiotic sulfamethoxazole and trimethoprim $(0.5 \mathrm{mg} / \mathrm{kg})$ was administrated via the drinking water for 12 days post transplantation. Three weeks after BM reconstitution peripheral blood $(0.2 \mathrm{~mL})$ was collected from the tail vein to determine enrichment in $\mathrm{GFP}^{+}$cells by fluorescence-activated cell sorting (FACS) analysis.

\subsection{Model of chronic kidney disease}

All operations were performed under isoflurane anesthesia. Three weeks after BM transplantation rats were randomly divided into two experimental groups: healthy controls $(\mathrm{n}=10)$ and rats with CKD $(\mathrm{n}=17)$. CKD was induced by two-stage subtotal nephrectomy (uninephrectomy of left kidney (UNX) followed 7 days later by $2 / 3$ removal of right kidney), as described previously [20,21]. Two weeks later CKD was confirmed by measuring serum creatinine and blood urea nitrogen (BUN).

\subsection{Implant material}

Solid cylindrical-shaped rods composed of the elastomeric copolymer PEOT/PBT of $1.75-0.25 \mathrm{~mm}$ in diameter and $1.5 \mathrm{~cm}$ in length were fabricated with a rapid prototyping unit33 (Envisiontec $\mathrm{GmbH}$, Gladbeck, Germany) used as melt extruder. Rods were composed of the co-polymer poly (ethylene oxide terephthalate)epoly (butylene terephthalate) (PEOT/PBT, Polyvation, The Netherlands), with a PEOT/ PBT weight percentage of 55/45 and $300 \mathrm{~g} / \mathrm{mol}$ molecular weight of the initial polyethylene glycol used for the copolymer reaction. The implant surface was modified by etching with chloroform as previously described [12,22]. Surface topography of all modified rods was evaluated using scanning electron microscopy (SEM). Rods were sterilized by gamma irradiation at a minimum dose of $25 \mathrm{kGy}$ (Synergy Health Ede, the Netherlands). The effect of gamma-radiation on the surface was evaluated using SEM.

\subsection{Implantation of polymeric rods}

Per rat, four rods were implanted in the subcutaneous space of the abdominal area. First pair of rods were inserted at 2 weeks after CKD induction and 5 weeks after BM transplantation, and left in place for 3 weeks. One week before rods extrusion another pair of rods were inserted for 1-week time point. Following a small horizontal incision of ca. $0.5 \mathrm{~cm}$, a longitudinal subcutaneous pocket was formed where the rods were inserted. The incision was closed using 4-0 vicryl sutures (Johnson \& Johnson, NJ, USA). The skin was closed intracutaneously. Rats directly received post operational analgesia via pre-operative injection of buprenorphine $(0.01-0.05 \mathrm{mg} / \mathrm{kg})$ and $2 \mathrm{oz}$ gel cups with Carprofen $(5 \mathrm{mg} / \mathrm{kg}$ ) were placed into the cages for up to 3 days postsurgery. One or three weeks after insertion of the rods, tissue capsules were harvested and animals were euthanized by $\mathrm{CO} 2$ asphyxiation. In short, a longitudinal incision lateral to the rod was made and the tissue capsule was gently removed from the surrounding tissue. After harvesting, rods could easily be extruded from the tissue capsule.

\subsection{Morphometric and histological analysis}

Tissue capsules containing rods were fixed in 4\% paraformaldehyde. After extrusion of the rods, tissue capsules were processed and embedded in paraffin. Serial cross sections of $5 \mathrm{~mm}$ of two parts of each tissue capsule were made for immunohistochemical and immunofluorescence analysis. To characterize the extracellular matrix, serial sections of each tissue capsule were stained with picrosirius red for collagen and Movat's stain for other extracellular matrix (ECM) components. Total collagen content was analyzed using QuickZyme Total Collagen Assay Kit (Biosciences, the Netherlands) according to the manufacturer protocol. In brief, five to ten $10 \mu \mathrm{m}$ tissue sections were hydrolyzed by $\mathrm{o} / \mathrm{n}$ incubation at $95^{\circ} \mathrm{C}$ in a heat block. Upon hydrolysis, $35 \mu \mathrm{l}$ was used for collagen quantification. The assay measured the total amount of hydroxyproline present in the sample after $90 \mathrm{~min}$ of incubation time, which represents all collagen-types present in the sample. The assay results in a chromogen with an absorbance maximum at $570 \mathrm{~nm}$.

Cellular composition of tissue capsules was characterized using immunohistochemistry, with antibodies against a-smooth muscle actin (1:1000; Dako M0851, CA, USA) for myofibroblasts, CD68 (1:300; Abcam Ab31630, Cambridge, UK) for macrophages and Ki67 (1:100; BD-Pharmigen 550609, CA, USA) for proliferating cells and visualized with 3,3\$-diaminobenzadine (DAB).

To visualize $\mathrm{GFP}^{+}$cells sections were stained with anti-GFP antibody (1:100; Abcam, ab13970, Cambridge, UK) with secondary Cy5 conjugated Goat anti-Chk IgY (1:500; Abcam ab97147, Cambridge, UK). For immunofluorescent staining of CD68 after primary antibody Alexa 568 conjugated goat anti mouse IgG1 (1:300; Molecular Probes A21124, OR, USA) was used. SMA was counterstained with Alexa 488 
conjugated secondary mouse IgG2a (1:250; Molecular Probes A21131, OR, USA). Stem/progenitor cell-like population was stained with CD133 (primary ab 1:200; Abcam Ab19898, Cambridge, UK) and secondary goat anti rabbit IgG Alexa 488 (1:250; Molecular Probes A11008, OR, USA). Anti-inflammatory macrophages were visualized by the double staining of CD68 and CD163 (1:400; Immunologic 1105C01, the Netherlands; secondary goat anti rabbit IgG Alexa 488 (1:250; Molecular Probes A11008, OR, USA). Nuclei were visualized with ProLong $^{\text {TM }}$ Gold Antifade Mountant with DAPI (Thermo Fisher P369, MA, USA). Negative controls were obtained using an isotype antibody and in addition for all stainings a positive control was taken along.

All slides were digitized using an automated microscopic scanner (Panoramic digital MIDI, 3DHISTECH, Budapest, Hungary). For the quantification of all immunofluorescence staining, the number of positive cells was counted in 8 random fields of view within the TC area at $60 \times\left(\mathrm{CD}^{+} 8^{+}\right.$and $\left.\mathrm{CD}^{+} 8^{+} / \mathrm{GFP}^{+}\right)$or $120 \times\left(\mathrm{SMA}^{+} / \mathrm{GFP}^{+} ; \mathrm{SMA}^{+} /\right.$ $\mathrm{GFP}^{+} / \mathrm{CD} 8^{+} ; \mathrm{CD} 68^{+} / \mathrm{CD} 163^{+}$and $\mathrm{CD} 133^{+} / \mathrm{GFP}^{+} / \mathrm{SMA}^{+}$) magnification, from which the mean was calculated. Quantification of bright field Ki67 staining was performed with HistoQuant software (3DHISTECH) by calculating \% DAB positive area from the total tissue capsule area.

\subsection{Flow cytometry and blood and BM analysis}

The peripheral blood was withdrawn from rat tail vein into tubes containing 15\% EDTA for FACS analysis. For the analysis of $\mathrm{GFP}^{+}$cells in the BM, complete BM was flushed out from femurs and tibia of rats post-lethality. Red blood cell lysis buffer (1.2 mL, Sigma, St Louis, MO, USA) was added into the tubes containing $0.1 \mathrm{~mL}$ blood and/or BM and incubated at $37^{\circ} \mathrm{C}$ for $5 \mathrm{~min}$ followed by addition of $10 \mathrm{~mL}$ PBS and centrifugation to remove the lysed red blood cells. The cells $\left(10^{6}\right.$ cells/ $\mathrm{mL}$ ) were resuspended in $50 \mathrm{~mL}$ FACS buffer (PBS containing 1\% BSA and $0.01 \%$ sodium azide) and incubated with Hoechst antibodies (Thermo Fisher, MA, USA) for life/dead cell gating. GFP fluorescence on the surface was determined by fluorescence-activated cell sorting analysis (FACS, LSR II; BD Biosciences, CA, USA). Data were analyzed using FACS-Diva software (BD Biosciences, CA, USA).

\subsection{RNA isolation, cDNA synthesis and $q P C R$}

Total RNA was extracted from VSMCs using Trizol reagent (Invitrogen, CA, USA) according to the manufacturer's protocol. RNA was reverse transcribed by M-MLV First-Strand Synthesis system (Invitrogen, CA, USA), and used for quantitative analysis of rat genes (Supplementary Table 1) with an SYBR Green Master Mix (Applied Biosystems, CA, USA). Ribosomal protein S15 (RPS15) was used as standard housekeeping gene. The relative mRNA expression levels were determined using $2[-\Delta \Delta \mathrm{C}(\mathrm{T})]$ method.

\subsection{Statistical analysis}

Results are expressed as mean \pm SEM and considered statistically significant for $\mathrm{P}<0.05$. T tests and Mann-Whitney tests for parametric and nonparametric data, respectively, were used as appropriate.

\section{Results}

\subsection{Surgical procedure}

\subsubsection{Generation of rats with GFP-labeled hematopoietic cells and chronic} kidney disease

To investigate the contribution of BM derived cells to TC formation, we established a rat model where cells of the hematopoietic lineage expressed GFP. SD rats were transplanted with BM cells derived from transgenic GFP-SD rats. No immunological rejection occurred, as all of the experimental animals underwent BM-transplantation survived and demonstrated high engraftment of donor-derived $\mathrm{GFP}^{+}$cells. Percentage of GFP ${ }^{+}$cells was evaluated by FACS analysis of the peripheral blood at three time points: 1) 3 weeks after BM transplantation; 2) 6 weeks later, when the polymeric rods were implanted; and 3) when the polymeric rods were excised from the TC, another 3 weeks later. The percentages of $\mathrm{GFP}^{+}$BMCs in the peripheral blood of the rats at these 3 time points were $74 \pm 1.6 \%$; $80 \pm 1.5 \%$; and $77 \pm 3 \%$, respectively. The percentage of $\mathrm{GFP}^{+}$cells in the BM at time of TC harvest was $72 \pm 3.6 \%$.

Three weeks after BM transplantation, 17 rats underwent a 5/6 nephrectomy procedure from which 8 rats survived (47\%). The healthy control group (WT) comprised of 10 animals with BM transplant but without the $5 / 6$ nephrectomy procedure.

The CKD condition was established and persisted for the duration of TC formation. At the time of TC harvest, histological analysis of the remaining kidney of CKD rats revealed enlarged sclerotic glomeruli, dilated tubuli, regions of tubular necrosis and cast formation (Supplementary fig.1). These structural changes coincided with elevated serum creatinine and BUN levels at the time of rod implantation and rod extrusion (mean creatinine levels: implantation-WT $0.4 \mathrm{mg}$ / $\mathrm{dL}$, vs. CKD $0.94 \mathrm{mg} / \mathrm{dL}, \mathrm{P}=0.0001$; extrusion-WT $0.48 \mathrm{mg} / \mathrm{dL}$ vs. CKD $1.1 \mathrm{mg} / \mathrm{dL} \mathrm{P}=0.0001$; mean BUN levels: implantation-WT $15.2 \mathrm{mg} / \mathrm{dL}$ vs. CKD $31.1 \mathrm{mg} / \mathrm{dL}, \mathrm{P}=0.0007$; extrusion-WT $18.6 \mathrm{mg}$ / dL vs. CKD $40.25 \mathrm{mg} / \mathrm{dL}, \mathrm{P}=0.0005)$.

The high mortality rate (53\%) of CKD animals was primarily due to uremia as creatinine and blood urea nitrogen levels in these animals were very high, emphasizing the severity of 5/6 nephrectomy model (data not shown).

\subsubsection{Implantation of the rods and TC harvest}

Fabrication of implanted material was performed as previously described [12]. To create a homogeneous porous surface along the rod, for optimal inflammatory cell recruitment and organization of collagen and myofibroblasts, rods were etched with chloroform. Chloroform etching was verified using SEM (Supplementary fig.2).

Two weeks after induction of CKD, 4 polymer rods were implanted into the subcutis of the rats in the abdominal area. TCs were harvested at 1- and 3-weeks after subcutaneous implantation of the rods. The study design is summarized in Fig. 1.

\subsection{Tissue capsule formation}

Cellular organization within the TC gradually changed from a disorganized, highly nucleated structure at 1-week, to circumferentially aligned tissue at 3-weeks in both WT and CKD groups. TCs were mainly composed of extracellular matrix components (Fig. 2a) and $\mathrm{SMA}^{+}$ myofibroblasts (Fig. 2b). The evolution of the TC formation was characterized by an initial accumulation of $\mathrm{CD}^{+} 8^{+}$macrophages in proximity to the synthetic rod at the 1-week time point, whereas at 3-weeks $\mathrm{CD} 8^{+}$cells were gradually dispersed through the entire TC volume (Fig. 2c). Furthermore, the number of $\mathrm{Ki}^{+} 7^{+}$proliferating cells at 3weeks reduced by $40 \%$ and $67 \%(\mathrm{P}=0.03)$ in WT and CKD animals, respectively, when compared to the 1-week time point (Fig. 2d). The collagen density gradually increased as the TC maturated, forming a well-defined circular structure at 3-weeks in both WT and CKD animals (Fig. 3a). Analysis of the total collagen content revealed increase in total collagen amount in the TCs at 3 weeks in both WT and CKD animals (WT: 54\% increase, $\mathrm{P}=0.02$; CKD: $61 \%$ increase, $\mathrm{P}=0.01$ ) when compared to TCs obtained at 1 week after rod implantation (Fig. 3b). No difference in collagen content was detected between WT and CKD animals, indicating that CKD state has no major influence on collagen synthesis in the TCs. 

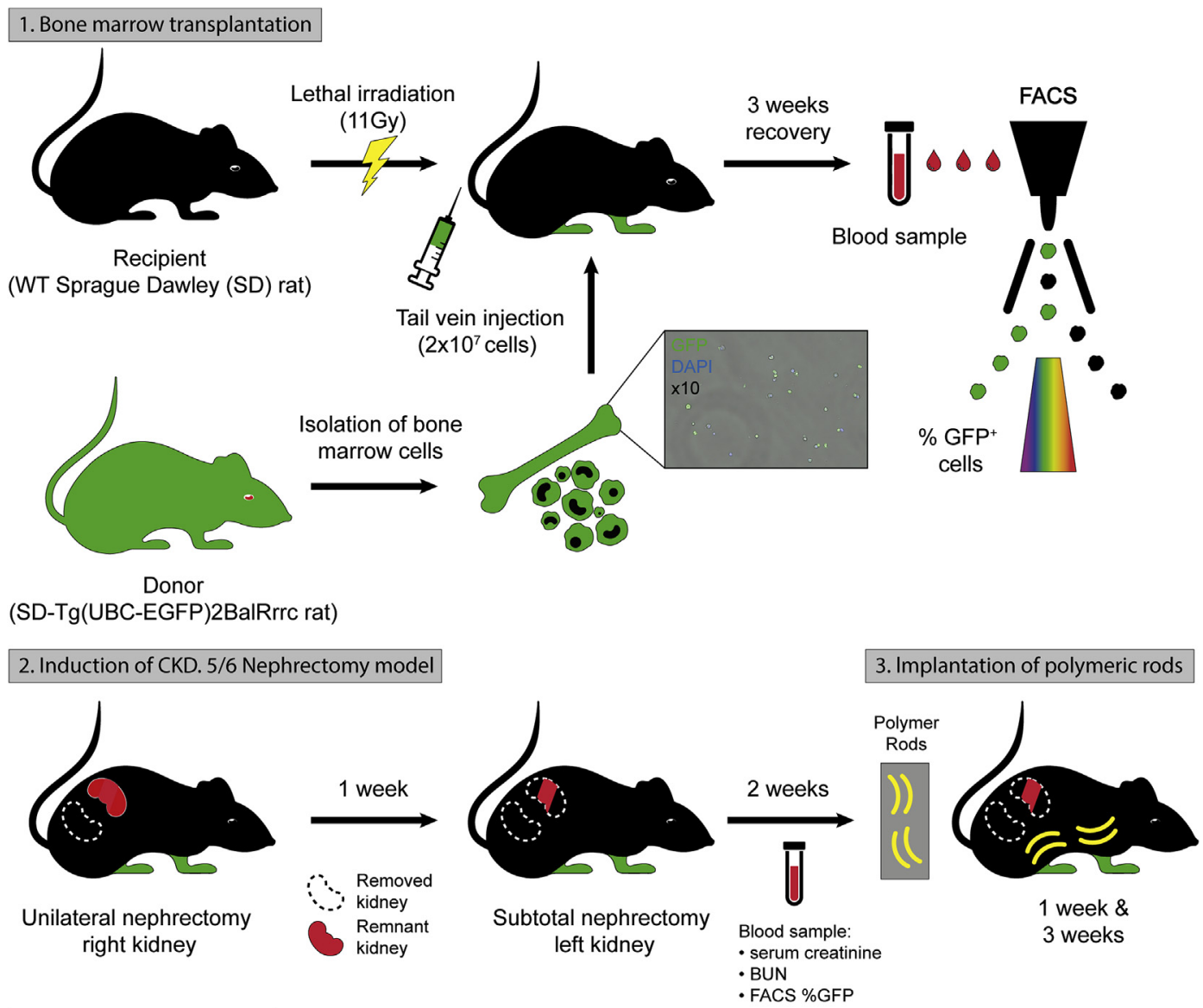

4. Harvest of tissue capsule

Histomorphometry and cellular composition (IHC, IF, RNA)

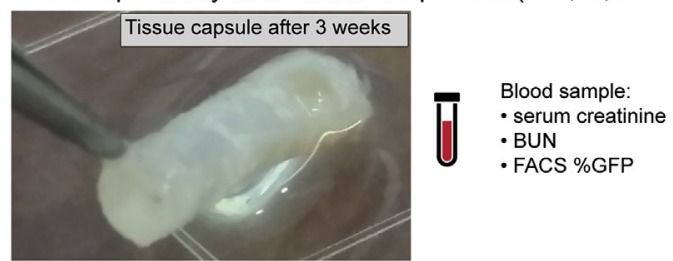

Fig. 1. Schematic representation of the project work flow. (1) $2 * 10^{7}$ of total bone marrow cells harvested from transgenic Sprague Dawley (SD) rats ubiquitously expressing green fluorescent protein (GFP) were injected into the tail vein of wild-type (WT) SD recipient rats; $n=27$. Three weeks after the bone marrow reconstitution percentage of $\mathrm{GFP}^{+}$cells in the peripheral blood of recipient rats was measured by FACS analysis. (2) 2-step induction of chronic kidney disease (CKD); 1) unilateral right side nephrectomy and 2) $2 / 3$ subtotal nephrectomy of the left kidney. Degree of CKD was confirmed by serum creatinine and blood urea nitrogen (BUN) levels 2 weeks after the procedure. (3) Polymeric rods were implanted into subcutaneous space of CKD and WT animals. (4) After 1 and 3 weeks implantation, rods together with formed fibrocellular tissue capsule were extruded and processed for further analysis. $n=10$ WT, $n=8$ CKD group. (For interpretation of the references to color in this figure legend, the reader is referred to the Web version of this article.)

\subsection{A minority of inflammatory cells within TCs originates from the bone marrow}

The number of $\mathrm{CD}^{+} 8^{+}$macrophages in the TCs at 3-weeks increased by $28 \%(\mathrm{P}=0.03)$ and $82 \%(\mathrm{P}=0.0006)$ in $\mathrm{WT}$ and $\mathrm{CKD}$ animals respectively, as compared to 1 -week (Fig. $4 \mathrm{a}$ and $\mathrm{b}$ ).

Analysis of $\mathrm{CD} 68^{+} / \mathrm{GFP}^{+}$cells within TC at 1 -week revealed that $11.2 \pm 1 \%$ and $16.9 \pm 2 \%$ of $\mathrm{CD}^{+} 8^{+}$cells originated from the bone marrow in WT and CKD group, respectively (Fig. 4a,c). The percentage of $\mathrm{BM}$-derived $\mathrm{CD}^{+} 8^{+} / \mathrm{GFP}^{+}$macrophages in $\mathrm{TC}$ at 3 -weeks was $15.4 \pm 2 \%$ and $11.3 \pm 1.3 \%$ in WT and CKD group, respectively (Fig. 4a,c). At 1-week time point, the percentage of $\mathrm{CD}^{+} 8^{+}$cells that expressed GFP was 1.5 times higher in the CKD group as compared to WT animals $(\mathrm{P}=0.03)$, whereas at 3-weeks this trend reversed (Fig. 4c).
The percentage of $\mathrm{CD} 68^{+} / \mathrm{GFP}^{+}$cells, from the CKD group, detected in the TC harvested at 3-weeks, was reduced by $33 \%$ as compared to the 1 -week time point $(\mathrm{P}=0.02)$, (Fig. 4c).

\subsection{Contribution of bone marrow derived cells to myofibroblasts population in mature TCs}

As described above, the TC harvested at 3-weeks was characterized by an increase in $\mathrm{SMA}^{+}$myofibroblasts and accumulation of collagen as compared to TCs obtained at 1-week after rod implantation (Fig. 2b; $3 \mathrm{a}, \mathrm{b})$. Analysis of the TC harvested at 3-weeks revealed that $36 \%$ and $35 \%$ of $\mathrm{SMA}^{+}$cells were originating from the BM as they were positive for GFP in WT and CKD group, respectively (Fig. 5a and b). Moreover, $29 \%$ and $23 \%$ of $\mathrm{SMA}^{+} / \mathrm{GFP}^{+}$myofibroblasts co-expressed a macrophage marker CD68 in the WT and CKD group, respectively (Fig. 5a,c), 




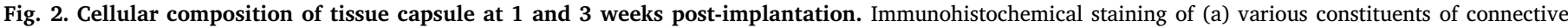

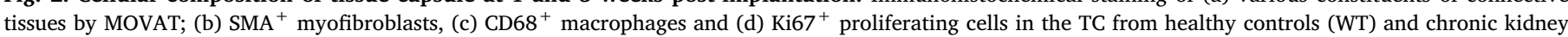
disease (CKD) rats harvested at 1 and 3 weeks post-implantation. $\mathrm{n}=10 \mathrm{WT}, \mathrm{n}=8$ CKD group.

suggesting a role for macrophage to myofibroblasts transition in TC formation.

\subsection{Tissue-resident macrophages in TC formation}

There is accumulating evidence that tissue-resident macrophages orchestrate tissue-repair responses [23]. Immunohistochemical analysis of the TCs obtained at 3 weeks after rod implantation revealed that $53 \%$ and $58 \%$ of $\mathrm{CD}^{+} 8^{+}$macrophages expressed the anti-inflammatory marker $\mathrm{CD}_{163^{+}}$, in WT and CKD animals respectively (Fig. 6a and b). Gene expression analysis confirmed the repair-associated phenotype of these cells, as mRNA levels of transforming growth factor beta (TGF $\beta$ ) in WT group was elevated by 2 -fold $(\mathrm{P}=0.03)$, whereas mRNA levels of the anti-inflammatory cytokine IL10 in CKD group was 2-fold higher $(\mathrm{P}=0.04)$ in the TCs harvested at 3-weeks as compared to 1-week time point (Fig. 6b).

\subsection{Discrete population of cells positive for stem/progenitor-cell marker CD133}

We observed a population of $\mathrm{GFP}^{+} / \mathrm{CD}^{-}$cells that accumulated predominantly at the outside border of the TC (Supplementary fig.3). Interestingly, nearly all of these $\mathrm{GFP}^{+} / \mathrm{CD}^{-} 8^{-}$cells expressed CD133, a marker of progenitor cells of various origin [24], in both WT and CKD animals. Moreover, $24 \%$ of the $\mathrm{CD}_{133^{+}} / \mathrm{GFP}^{+}$cells co-expressed SMA (Fig. 7a and b) indicating that BM derived hematopoietic stem cells can serve as direct precursors to myofibroblasts in mature TCs.

\section{Discussion}

In the present study, we showed that both BM-derived and tissueresident cells contribute to TC formation upon subcutaneous polymeric rod implantation. Surprisingly, only $13 \%$ of the macrophages within the TC originated from the $\mathrm{BM}$, whereas $36 \%$ of the myofibroblast originated from $\mathrm{BM}$ precursors. A substantial number of $\mathrm{SMA}^{+}$bone marrow derived myofibroblasts co-expressed CD68, highlighting the role of the macrophage-to-myofibroblast transition in the formation of the TC. During the maturation of the TC, the cellular response predominantly displayed repair associated characteristics. Importantly, the CKD condition did not significantly affect the process of TC formation.

\subsection{Tissue-resident and BM-derived cells both contribute to the inflammatory response upon polymer rod implantation}

Several studies have shown that the encapsulation of the foreign body is initiated with an inflammatory response, mainly through the activity of macrophages [14,15,25-27]. In this study, we also observed that along the inner border - adjacent to the polymeric rod - the tissue capsules were mainly composed of $\mathrm{CD} 68^{+}$macrophages. Remarkably, only a minority of the macrophages within the TC originated from the bone marrow, as only $13 \%$ of the total $\mathrm{CD} 8^{+}$population co-expressed GFP. Several studies suggest that cells within the local tissue environment, such as tissue-resident macrophages, also contribute to the foreign body response and play major role in the formation of engineered tissue [28-30]. Tissue-resident macrophages consist of a mixture of embryonic- and adult-hematopoietic stem cell-derived macrophages, which have the capacity to self-renewal throughout adulthood [31,32].

Here, we show that the maturation of the TC is associated with a $40 \%$ increase in tissue-resident $\mathrm{CD} 68^{+} / \mathrm{CD} 163^{+}$macrophages along with increase in IL10 and pro-fibrotic TGF $\beta$ mRNA levels within TCs. Besides, we did not observe a significant difference in $\mathrm{CD}^{+} 8^{+} / \mathrm{CD} 163^{+}$ macrophage population between CKD (46\% of total macrophages) and WT animals (38\%). Myofibroblast content was also similar between the groups. The latter most likely explains the similarity in collagen content in TCs as collagen is predominantly synthesized by (myo)fibroblasts. 
a.



CKD 1w
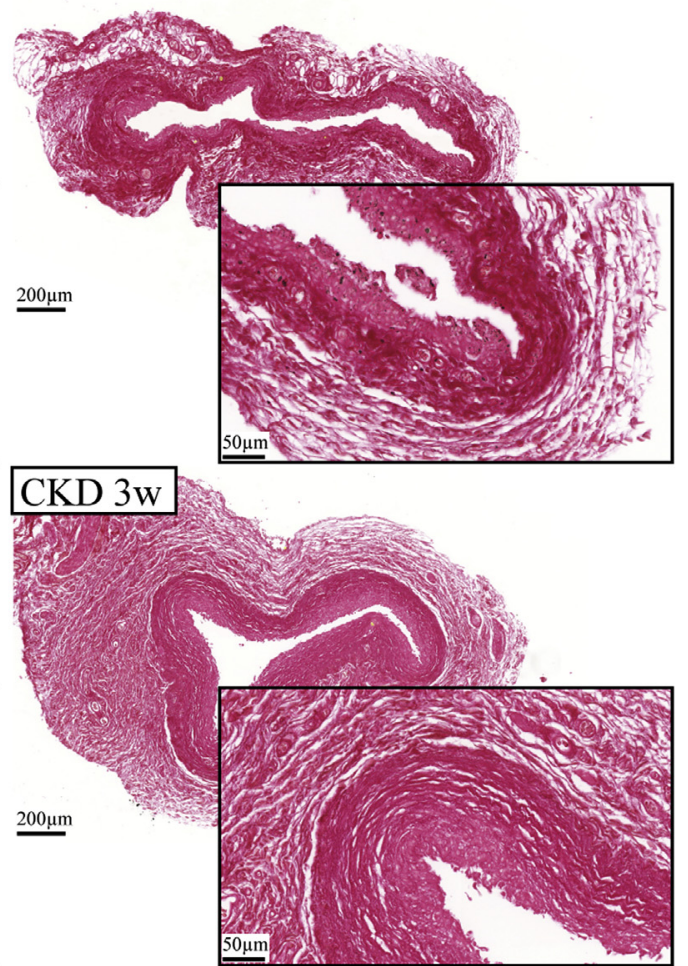

b.

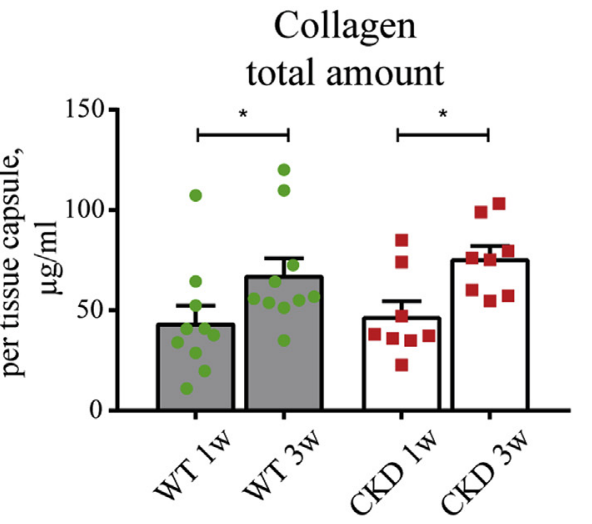

Fig. 3. Changes in collagen content over the time course of tissue capsule maturation. (a) Picrosirius red staining of the collagen. The collagen density gradually increased forming a well-defined circular structure at 3 weeks in both WT and CKD animals. (b) Analysis of the total collagen amount measured by QuickZyme Total Collagen Assay Kit. Significant increase in collagen content within WT and CKD groups was observed. $\left({ }^{*}\right)$ P $<0.05 ; n=10$ WT, $n=8$ CKD group. (For interpretation of the references to color in this figure legend, the reader is referred to the Web version of this article.)

\subsection{Macrophages as precursors of myofibroblasts}

During the development of the TC, we observed a gradual transition from granulation tissue towards circumferentially aligned SMA ${ }^{+}$myofibroblasts, whereas a substantial proportion of the myofibroblasts in the TCs were derived from hematopoietic BMCs. The ability of BMderived cells to differentiate into smooth muscle-like cells was first described by Campbell and coworkers in their experimental work on TC formation in the peritoneal cavity [33]. Subsequent studies from the same group confirmed the plasticity of peritoneal macrophages and their ability to transdifferentiate from a myeloid to mesenchymal phenotype [34]. In our model, $26 \%$ of myofibroblasts originated from BM-derived macrophages, which illustrates the importance of macrophage-to-myofibroblast transition during the TC development.

\subsection{Contribution of bone marrow progenitor cells to TC formation}

Possibly, other than BM-derived and/or tissue resident macrophages can contribute to TC formation. A recent study by Wang et al. showed that Sox $10^{+}$adult mouse stem cells found within the stroma of subcutaneous loose connective tissues, can contribute to encapsulation, fibrosis, and microvascularization of biomaterials upon implantation [35]. Interestingly, we observed a population of $\mathrm{CD} 133^{+} / \mathrm{GFP}^{+}$cells at the outer border of the TCs. Previous studies revealed that the membrane bound glycoprotein CD133 is expressed in mesenchymal stem cells (MSCs) [36] and stromal cells [37] within the BM. Both MSCs and stromal cells can give rise to human osteoblasts, adipocytes, chondrocytes as well as fibroblasts [38,39]. In this study, 24\% $\mathrm{CD}_{133^{+}}$/ $\mathrm{GFP}^{+}$cells were positive for $\mathrm{SMA}^{+}$suggesting that $\mathrm{CD} 133^{+}$BM-derived cells can contribute to the myofibroblast population in mature 




b.

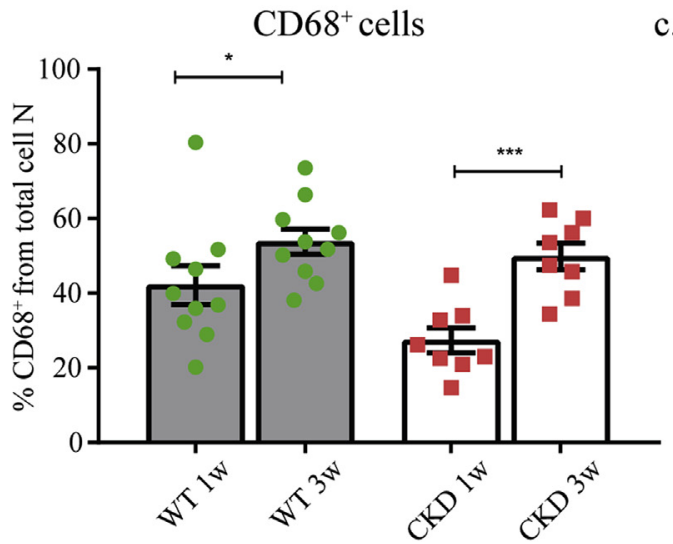

c.

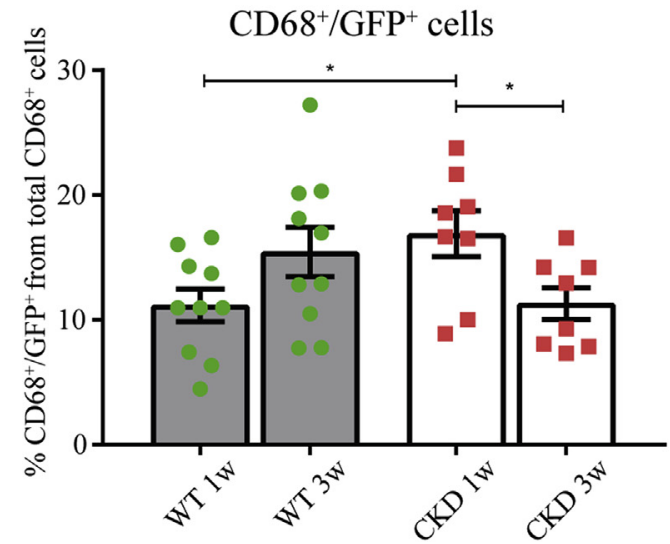

Fig. 4. Macrophages in tissue capsule formation. (a) Immunofluorescence staining of $\mathrm{CD}_{6} 8^{+}$macrophage marker (red color) and bone marrow derived GFP marker (light blue color). $\mathrm{CD}^{+} 8^{+} / \mathrm{GFP}^{+}$bone marrow derived macrophages (white arrows) was detected in the TC harvested at 1 and 3 weeks in WT and CKD group. (b) Quantification of total $\mathrm{CD}^{+} 8^{+}$macrophages within TC harvested at 1 and 3 weeks in WT and CKD animals. (c) Quantification of CD68 ${ }^{+} / \mathrm{GFP}^{+}$bone marrow derived macrophages from total $\mathrm{CD}^{+} 8^{+}$population. Nuclei DAPI (blue color). (*) $\mathrm{P}<0.05$; (**) $\mathrm{P}<0.001 ; \mathrm{n}=10 \mathrm{WT}, \mathrm{n}=8 \mathrm{CKD}$ group. (For interpretation of the references to color in this figure legend, the reader is referred to the Web version of this article.)

tissue capsules.

\subsection{CKD does not influence the cellular response during TC formation}

As discussed above, the process of TC formation involves an acute inflammatory response, followed by chronic inflammation and fibrosis culminating in the encapsulation of the implanted biomaterial. CKD is a pro-fibrotic condition associated with tissue scarring as well as kidney and cardiac fibrosis [40-42]. Excessive TGF $\beta$ signaling, which has been implicated in epithelial cells and fibroblasts in CKD [41], can potentially enhance the process of TC formation in the subcutaneous space. On the other hand, CKD is associated with impaired function of both the innate and adaptive immune systems [17]. Circulating CD34 ${ }^{+}$ progenitor cells are markedly reduced in patients with CKD. In addition, monocyte-macrophages are more prone to apoptosis in CKD patients' [43], which could also negatively influence TC formation in CKD patients.

In the present study, we did not observe a significant effect of CKD on the cellular response upon implantation of the polymer rod. We hypothesize that the local foreign body response upon implantation of 


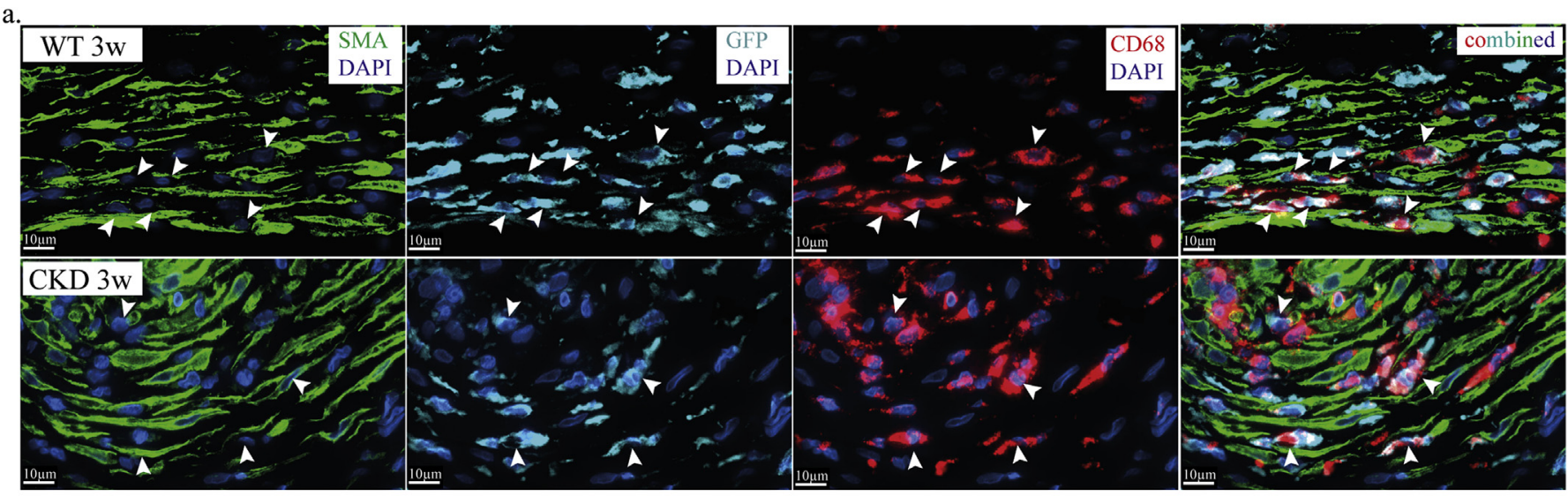

b.

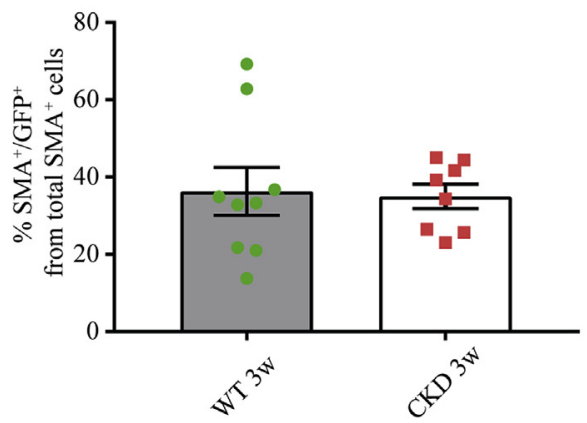

c.

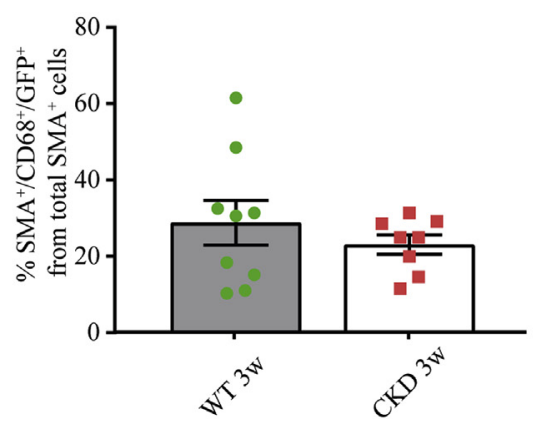

Fig. 5. Macrophage to myofibroblasts transition. (a) Immunofluorescence staining of SMA ${ }^{+}$myofibroblasts (green color) co-expressing bone marrow derived GFP marker (light blue color) and $\mathrm{CD} 68^{+}$macrophage marker (red color). Population of SMA ${ }^{+} / \mathrm{GFP}^{+} / \mathrm{CD} 8^{+}$myofibroblasts (white arrows) was detected in TC at 3 weeks in both groups. Quantification of (b) SMA ${ }^{+} / \mathrm{GFP}^{+}$and (c) $\mathrm{SMA}^{+} / \mathrm{GFP}^{+} / \mathrm{CD}^{+} 8^{+}$myofibroblasts from total SMA ${ }^{+}$population within TC harvested at 3 weeks in WT and CKD group. Nuclei DAPI (blue color). $n=9$ WT, $n=8$ CKD group. (For interpretation of the references to color in this figure legend, the reader is referred to the Web version of this article.)

the polymer rod substantially differs from chronic inflammation and subsequent tissue fibrosis as observed in various organs of patients with CKD.

After only 3 weeks, tissue capsules were well matured, indicating the importance of the acute response and that the local environment within subcutaneous space is sufficient to maintain the process of TC formation.

Some aspects of our study require further discussion. One limitation in particular is the imperfect efficacy of the bone marrow transplantation, as only $75-80 \%$ of the cells in the peripheral blood were $\mathrm{GFP}^{+}$ after BM-transplantation. As a consequence, the contribution of bone marrow derived cells in TC formation might be underestimated.

Our technology of tissue engineered blood vessels is aimed for patients with stage 5 of CKD which is defined as ESRD, when renal replacement therapy is required to survive. It is important to emphasize that the 5/6-nephrectomy model used in the current study does not fully resemble ESRD, as the glomerular filtration rate (GFR) in this model is around $29-15 \%$ of normal (CKD stage 4). Therefore, caution is required when extrapolating these results to humans as TC formation in these rats might be different when compared to dialysis patients. Furthermore, the pathophysiological mechanisms underlying CKD are also different between 5/6 nephrectomy animals and patients with CKD. Nevertheless, the 5/6-nephrectomy model in rats remains the most valuable and extensively investigated animal model mimicking human CKD [44-47].

Another limitation of this study is the inability to measure the mechanical strength of the TCs, an important parameter defining TC suitability for vascular grafting. However, a recent study performed in pigs demonstrates that the burst pressure and suture retention strength of the autologous TCs are sufficient to allow safe implantation in the arterial circulation [13].

\section{Conclusion}

This study illustrates that both BM-derived and resident cells contribute to the process of tissue response directed to a polymer rod that culminates in the formation of a collagen rich fibrocellular tissue capsule. BM-derived- as well as tissue resident macrophages serve as precursors of myofibroblasts in matured TCs. Notably, the presence of CKD does not significantly alter the process of TC formation, which supports the suitability of our autologous vascular tissue engineering approach for future clinical use in CKD patients.

\section{Disclosure}

The authors confirm that this article content has no conflicts of interest to disclose.

\section{Data availability}

The raw data required to reproduce these findings are available to download from [Bezhaeva, Taisiya (2018), "Data for: Contribution of bone marrow-derived cells to in situ engineered tissue capsules in a rat model of chronic kidney disease", Mendeley Data, v1https://doi.org/ 10.17632/7crw3h6327.1].

\section{Acknowledgements}

This study was supported by a VIDI grant (016.156.328) awarded to J.I. Rotmans and funding from the National Institute of Health 
a.
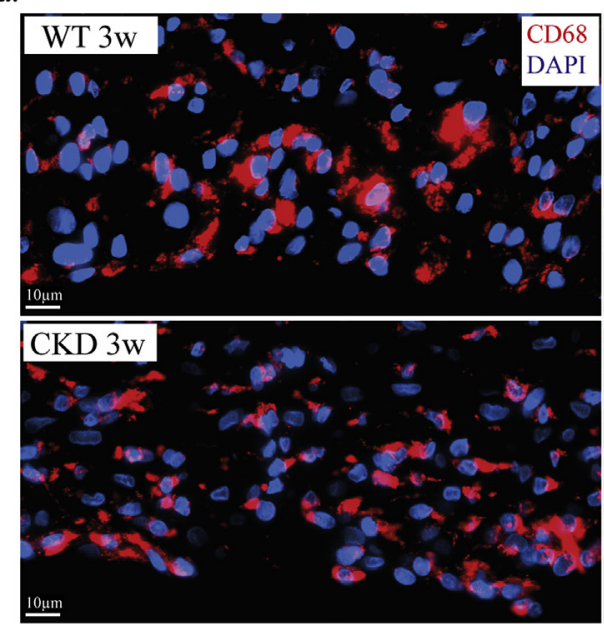

b.

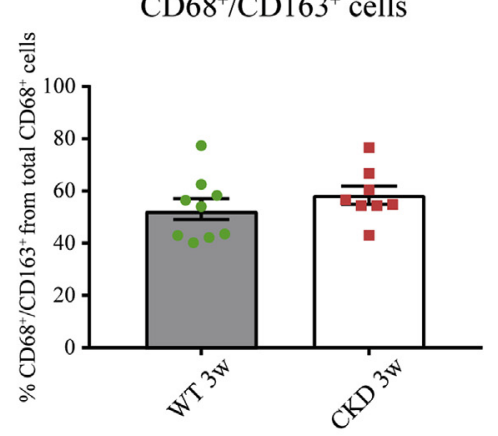

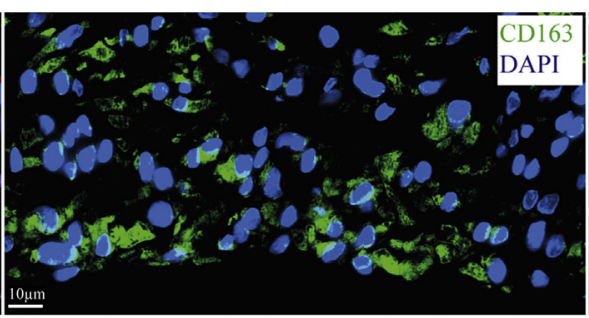
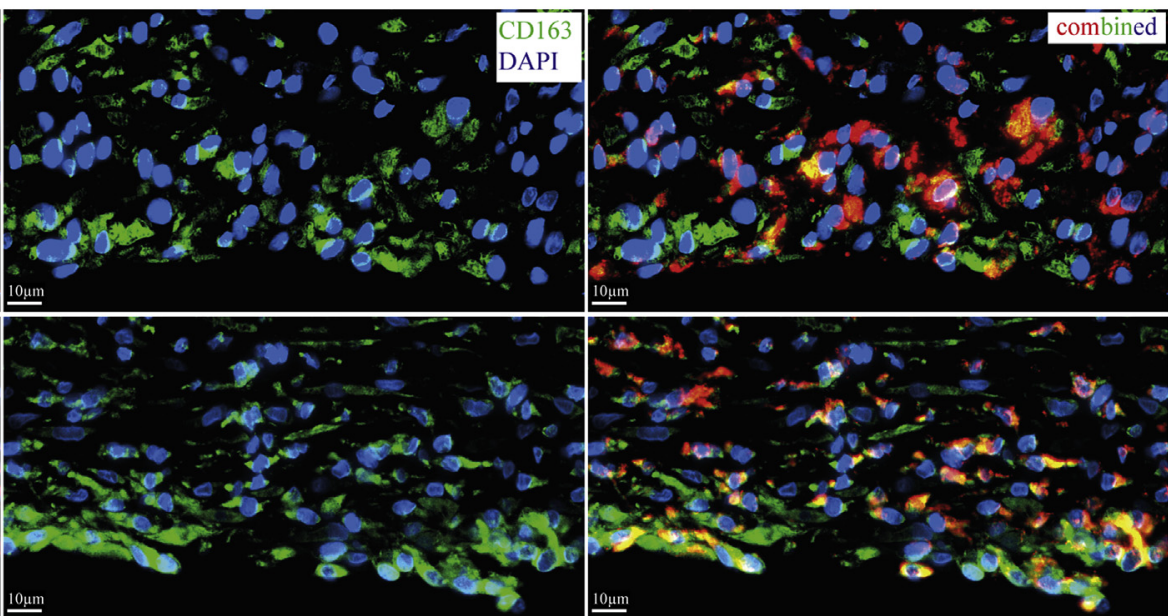

c.

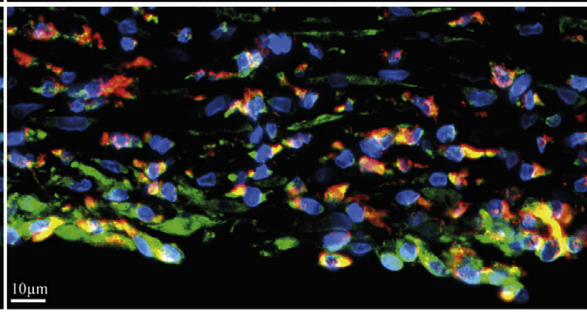

IL10
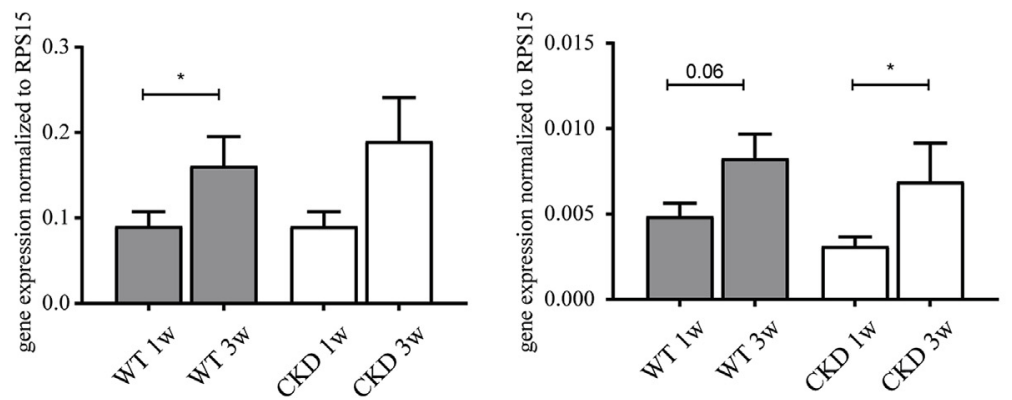

Fig. 6. Tissue resident macrophages in tissue capsule formation. (a) Immunofluorescence staining of $\mathrm{CD}_{68}{ }^{+}$macrophages (red color) positive for tissue resident marker CD163 (green color). (b) Quantification of the $\mathrm{CD} 68^{+} / \mathrm{CD} 163^{+}$tissue resident macrophages from total $\mathrm{CD} 68^{+}$cells. (c) Gene expression analysis of transforming growth factor beta (TGF $\beta$ ) and anti-inflammatory cytokine IL10 in the TC at 1 and 3 weeks in WT and CKD group. Nuclei DAPI (blue color). (*) $\mathrm{P}=0.05 ; \mathrm{n}=8 \mathrm{WT}, \mathrm{n}=8 \mathrm{CKD}$ group. (For interpretation of the references to color in this figure legend, the reader is referred to the Web version of this article.)

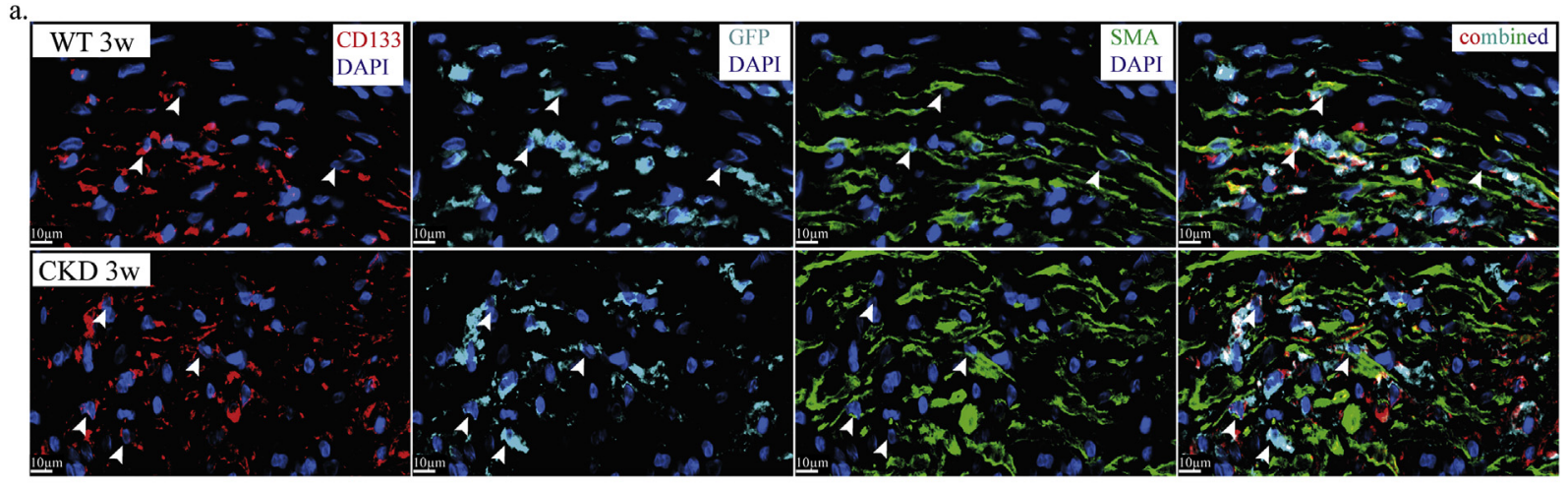

b.

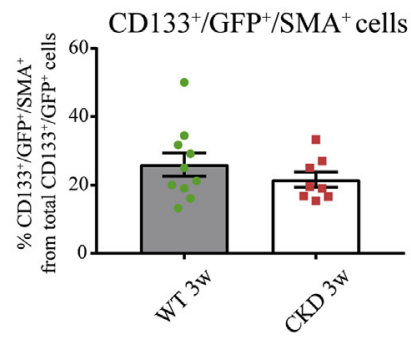

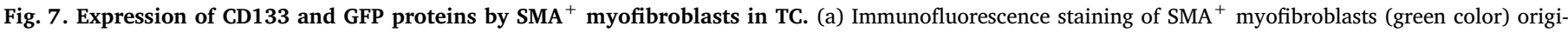

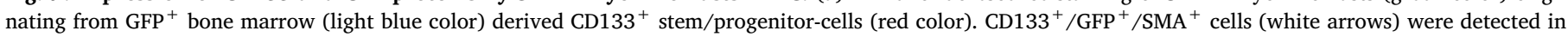
the TC at 3 weeks in both experimental groups detected. (b) Quantification of CD133 ${ }^{+} / \mathrm{GFP}^{+} / \mathrm{SMA}^{+}$within the TC at 3 weeks in WT and CKD group. DAPI-nuclei blue. $\mathrm{n}=10 \mathrm{WT}, \mathrm{n}=8 \mathrm{CKD}$ group. (For interpretation of the references to color in this figure legend, the reader is referred to the Web version of this article.) 
(EB012240 and HL083900) awarded to S. Li. We would like to thank Reshma A. Lalai for her excellent assistance in performing experiments and data analysis. Dr. Kei S. Iwamoto, from UCLA Radiation Oncology department for his excellent assistance in bone marrow transplantation experiments.

Flow cytometry was performed in the UCLA Jonsson Comprehensive Cancer Center (JCCC) and Center for AIDS Research Flow Cytometry Core Facility that is supported by National Institutes of Health awards P30 CA016042 and 5P30 AI028697, and by the JCCCJCCC, the UCLA AIDS Institute, the David Geffen School of Medicine at UCLA, the UCLA Chancellor's Office, and the UCLA Vice Chancellor's Office of Research.

\section{Appendix A. Supplementary data}

Supplementary data to this article can be found online at https:// doi.org/10.1016/j.biomaterials.2018.12.014.

\section{References}

[1] M. Diodato, E.G. Chedrawy, Coronary artery bypass graft surgery: the past, present, and future of myocardial revascularisation, Surgery research and practice 2014 (2014) 726158

[2] A. Kainz, et al., Prediction of Prevalence of Chronic Kidney Disease in Diabetic Patients in Countries of the European Union up to 2025, Nephrology, dialysis, transplantation : official publication of the European Dialysis and Transplant Association - European Renal Association 30 Suppl 4, iv113-118 (2015).

[3] D. Lloyd-Jones, et al., Heart disease and stroke statistics-2010 update: a report from the American Heart Association, Circulation 121 (2010) e46-e215.

[4] T. Lee, et al., Comparative analysis of cellular phenotypes within the neointima from vein segments collected prior to vascular access surgery and stenotic arteriovenous dialysis accesses, Semin. Dial. 27 (2014) 303-309.

[5] R. Friedl, et al., Intimal hyperplasia and expression of transforming growth factorbeta1 in saphenous veins and internal mammary arteries before coronary artery surgery, Ann. Thorac. Surg. 78 (2004) 1312-1318.

[6] J.I. Rotmans, et al., Hemodialysis access graft failure: time to revisit an unmet clinical need? J. Nephrol. 18 (2005) 9-20.

[7] S. Aslam, F. Vaida, M. Ritter, R.L. Mehta, Systematic review and meta-analysis on management of hemodialysis catheter-related bacteremia, J. Am. Soc. Nephrol. : JASN (J. Am. Soc. Nephrol.) 25 (2014) 2927-2941.

[8] P. Roy-Chaudhury, et al., Venous neointimal hyperplasia in polytetrafluoroethylene dialysis grafts, Kidney Int. 59 (2001) 2325-2334.

[9] S. Pashneh-Tala, S. MacNeil, F. Claeyssens, The Tissue-engineered Vascular Graftpast, Present, and Future, Tissue engineering. Part B, Reviews (2015).

[10] J. Yu, et al., The effect of stromal cell-derived factor-1alpha/heparin coating of biodegradable vascular grafts on the recruitment of both endothelial and smooth muscle progenitor cells for accelerated regeneration, Biomaterials 33 (2012) 8062-8074.

[11] W.J. Geelhoed, L. Moroni, J.I. Rotmans, Utilizing the foreign body response to grow tissue engineered blood vessels in vivo, Journal of cardiovascular translational research 10 (2017) 167-179.

[12] T.C. Rothuizen, et al., Tailoring the foreign body response for in situ vascular tissue engineering, Tissue Eng. C Methods 21 (2015) 436-446.

[13] T.C. Rothuizen, et al., Development and evaluation of in vivo tissue engineered blood vessels in a porcine model, Biomaterials 75 (2016) 82-90.

[14] J.M. Anderson, A. Rodriguez, D.T. Chang, Foreign body reaction to biomaterials, Semin. Immunol. 20 (2008) 86-100.

[15] W. Kenneth Ward, A review of the foreign-body response to subcutaneously-implanted devices: the role of macrophages and cytokines in biofouling and fibrosis, Journal of diabetes science and technology 2 (2008) 768-777.

[16] P.E. Westerweel, et al., Impaired endothelial progenitor cell mobilization and dysfunctional bone marrow stroma in diabetes mellitus, PLoS One 8 (2013) e60357.

[17] S. Kato, et al., Aspects of immune dysfunction in end-stage renal disease, Clin. J. Am. Soc. Nephrol. : CJASN 3 (2008) 1526-1533.

[18] M. Teraa, et al., Bone marrow alterations and lower endothelial progenitor cell numbers in critical limb ischemia patients, PLoS One 8 (2013) e55592.

[19] C. Lois, E.J. Hong, S. Pease, E.J. Brown, D. Baltimore, Germline transmission and tissue-specific expression of transgenes delivered by lentiviral vectors, Science (New York, N.Y.) 295 (2002) 868-872.

[20] A. van Koppen, et al., Healthy bone marrow cells reduce progression of kidney failure better than CKD bone marrow cells in rats with established chronic kidney disease, Cell Transplant. 21 (2012) 2299-2312.

[21] A. van Koppen, M.C. Verhaar, L.G. Bongartz, J.A. Joles, 5/6th nephrectomy in combination with high salt diet and nitric oxide synthase inhibition to induce chronic kidney disease in the Lewis rat, J. Vis. Exp. 77 (2013) e50398, https://doi. org $/ 10.3791 / 50398$.

[22] F.F. Damanik, T.C. Rothuizen, C. van Blitterswijk, J.I. Rotmans, L. Moroni, Towards an in vitro model mimicking the foreign body response: tailoring the surface properties of biomaterials to modulate extracellular matrix, Sci. Rep. 4 (2014) 6325.

[23] A. Mantovani, et al., The chemokine system in diverse forms of macrophage activation and polarization, Trends Immunol. 25 (2004) 677-686.

[24] A.H. Yin, et al., AC133, a novel marker for human hematopoietic stem and progenitor cells, Blood 90 (1997) 5002-5012.

[25] K.M. Miller, R.A. Huskey, L.F. Bigby, J.M. Anderson, Characterization of biomedical polymer-adherent macrophages: interleukin 1 generation and scanning electron microscopy studies, Biomaterials 10 (1989) 187-196.

[26] M.G. Patino, M.E. Neiders, S. Andreana, B. Noble, R.E. Cohen, Cellular inflammatory response to porcine collagen membranes, J. Periodontal. Res. 38 (2003) 458-464.

[27] T. Lucas, et al., Differential roles of macrophages in diverse phases of skin repair, J. Immunol. 184 (2010) 3964-3977 (Baltimore, Md. : 1950).

[28] L.C. Davies, S.J. Jenkins, J.E. Allen, P.R. Taylor, Tissue-resident macrophages, Nat. Immunol. 14 (2013) 986-995.

[29] Y. Okabe, R. Medzhitov, Tissue biology perspective on macrophages, Nat. Immunol. 17 (2015) 9-17.

[30] J.F. Cailhier, et al., Conditional macrophage ablation demonstrates that resident macrophages initiate acute peritoneal inflammation, J. Immunol. 174 (2005) 2336-2342 (Baltimore, Md. : 1950).

[31] D. Hashimoto, et al., Tissue-resident macrophages self-maintain locally throughout adult life with minimal contribution from circulating monocytes, Immunity 38 (2013) 792-804.

[32] C. Dollinger, et al., Incorporation of resident macrophages in engineered tissues: multiple cell type response to microenvironment controlled macrophage-laden gelatine hydrogels, Journal of tissue engineering and regenerative medicine 12 (2018) $330-340$.

[33] J.H. Campbell, J.L. Efendy, C. Han, A.A. Girjes, G.R. Campbell, Haemopoietic origin of myofibroblasts formed in the peritoneal cavity in response to a foreign body, $\mathrm{J}$. Vasc. Res. 37 (2000) 364-371.

[34] J.E. Mooney, et al., Cellular plasticity of inflammatory myeloid cells in the peritoneal foreign body response, Am. J. Pathol. 176 (2010) 369-380.

[35] D. Wang, et al., Sox10 (+) adult stem cells contribute to biomaterial encapsulation and microvascularization, Sci. Rep. 7 (2017) 40295

[36] T. Tondreau, et al., Mesenchymal stem cells derived from CD133-positive cells in mobilized peripheral blood and cord blood: proliferation, Oct4 expression, and plasticity, Stem cells (Dayton, Ohio) 23 (2005) 1105-1112.

[37] B. Bakondi, J.L. Spees, Human CD133-derived bone marrow stromal cells establish ectopic hematopoietic microenvironments in immunodeficient mice, Biochem. Biophys. Res. Commun. 400 (2010) 212-218.

[38] P. Bianco, M. Riminucci, S. Gronthos, P.G. Robey, Bone marrow stromal stem cells: nature, biology, and potential applications, Stem cells (Dayton, Ohio) 19 (2001) $180-192$.

[39] Y. Jiang, et al., Pluripotency of mesenchymal stem cells derived from adult marrow, Nature 418 (2002) 41-49.

[40] D.M. Charytan, et al., Increased concentration of circulating angiogenesis and nitric oxide inhibitors induces endothelial to mesenchymal transition and myocardial fibrosis in patients with chronic kidney disease, Int. J. Cardiol. 176 (2014) 99-109.

[41] S. Xavier, et al., Curtailing endothelial TGF-beta signaling is sufficient to reduce endothelial-mesenchymal transition and fibrosis in CKD, J. Am. Soc. Nephrol. : JASN (J. Am. Soc. Nephrol.) 26 (2015) 817-829.

[42] H.A. Mutsaers, E.G. Stribos, G. Glorieux, R. Vanholder, P. Olinga, Chronic kidney disease and fibrosis: the role of uremic retention solutes, Front. Med. 2 (2015) 60

[43] F.H. Bahlmann, T. Speer, D. Fliser, Endothelial progenitor cells in chronic kidney disease, Nephrol. Dial. Transplant. : official publication of the European Dialysis and Transplant Association - European Renal Association 25 (2010) 341-346.

[44] H. Lu, X. Lei, C. Klaassen, Gender differences in renal nuclear receptors and aryl hydrocarbon receptor in 5/6 nephrectomized rats, Kidney Int. 70 (2006) 1920-1928.

[45] H.C. Yang, Y. Zuo, A.B. Fogo, Models of chronic kidney disease, Drug Discov. Today Dis. Model. 7 (2010) 13-19.

[46] O. Tsuprykov, et al., The dipeptidyl peptidase inhibitor linagliptin and the angiotensin II receptor blocker telmisartan show renal benefit by different pathways in rats with 5/6 nephrectomy, Kidney Int. 89 (2016) 1049-1061.

[47] J. Bai, et al., Netrin-1 attenuates the progression of renal dysfunction by blocking endothelial-to-mesenchymal transition in the 5/6 nephrectomy rat model, BMC Nephrol. 17 (2016) 47. 